\title{
A Model of Protection of Intangible Cultural Heritage by Commercial Three-Dimensional Animation - Taking "Little Master of Brocade" as an Example
}

\author{
Cao Yang ${ }^{1}$ \\ ${ }^{1}$ Faculty of Nanjing Normal University Fine Arts School, China \\ Correspondent: Cao Yang, Faculty of Nanjing Normal University Fine Arts School, China. E-mail: \\ kent_1019@163.com
}

Received: August 11, 2017

Accepted: August 24, 2016

Online Published: September 27, 2017

doi:10.5539/ach.v10n1p1

URL: https://doi.org/10.5539/ach.v10n1p1

\begin{abstract}
Though China has carried out protection of intangible cultural heritage by three-dimensional animation, to protect intangible cultural heritage by commercial three-dimensional animation still requires further discussion and promotion. "Little Master of Brocade" (Yun Jing Xiao Dang Jia) is a cartoon gaining a good reputation at home and abroad and it has achieved certain economic benefits and social and cultural benefits in respect of protection of intangible cultural heritage. On the basis the status of protection of intangible cultural heritage by three-dimensional animation, this paper discussed a new model and the future trend of protection of intangible cultural heritage by commercial three-dimensional animation by taking "Little Master of Brocade" (Yun Jing Xiao Dang Jia) as an example.
\end{abstract}

Keywords: Commercial three-dimensional animation, Protection of intangible cultural heritage, Nanjing Brocade

\section{Status of Protection of Intangible Cultural Heritage by three-Dimensional Animation}

By retrieving "intangible cultural heritage" from foreign English databases, it was found that there were few special articles relenting to studies on protection and development of intangible cultural heritage by three-dimensional (3D) animation. Meanwhile, according to retrieval results from Chinese databases, domestic research findings about protection of intangible cultural heritage by three-dimensional animation were also rare. Though China is abundant in intangible cultural heritage, its protection of intangible cultural heritage by three-dimensional animation is later than developed countries. Internationally, Massimiliano Pieraccini et al. from the University of Florence, Italy summarized the brief history of application of the technology of 3D digitalization and data acquisition to protection of cultural heritage and focused on investigation of the incentive mechanism, existing problems and technical specification etc. According to application tests with different kinds of digitalization technology, they held that the 3D technology had been fully developed and widely used in the field of protection of cultural heritage.

In China, some research projects on protection of intangible cultural heritage with three-dimensional animation have achieved preliminary results. For example, in the two projects of the CAD\&CG State Key Laboratory of Zhejiang University, namely the "Research on the key technology for digitized emergent protection and development of folk performing arts" and the "Digitized aided design system of Yunnan's bornite handicraft", protection and development are still at a testing stage and it still needs some time to transform research results into the practical application. At present, protection of intangible cultural heritage by three-dimensional animation is mainly supported by the government or commonweal organizations and generally generates no market profit.

The main stages of the protection of intangible cultural heritage by three-dimensional animation are: 3D acquisition and storage, restoration and recurrence of virtual reality, propagation and sharing, and protection and development.

1) $3 \mathrm{D}$ acquisition and storage: in addition to traditional computer modeling, the $3 \mathrm{D}$ model scanning technology can also be applied to conversion of tools, work environments, raw material and finished products of intangible cultural heritage into 3D models. For instance, data acquisition of cloisonné is carried out with the 3D laser scanner to obtain 3D point cloud data of its surface. Then, through the digital modeling technology, prolongation and modification of the scanned data is conducted to realize retrievable high-precision high-resolution 3D model data 
of intangible cultural heritage in respect of folk arts. In addition to model scanning, by applying the motion capture technology, motion data of creation and performance can be collected and transformed into digital information that can be processed and stored by computers.

2) Restoration and recurrence of virtual reality: by using the technology of virtual reality, 3D models obtained during acquisition are restored to simulate and reproduce the reality effect. In terms of recurrence of intangible cultural heritage, solutions for complete and systematic recurrence of intangible cultural heritage are produced by adopting the technology of 3D virtual reality. Especially, the technology of virtual reality can realize comprehensive simulation of senses of sight, hearing and touch etc.

3) Propagation and sharing: in respect of propagation of intangible cultural heritage, major contributions of the three-dimensional animation are reflected in display and sharing platforms of digital resources, such as digital museums, digital libraries and digital archives. These platforms are primarily divided into two forms: data platforms and experience platforms, which can be combined with each other or exert their special strengths. By establishing websites and connecting to databases, a retrieval platform can realize users' consulting and retrieving of relevant resources of intangible cultural heritage at any time and some online museums, such as the China Intangible Cultural Heritage Website · Digital Museum of China Intangible Cultural Heritage launched on June 9, 2006, provide declaration channels of intangible cultural heritage and communication platforms for protection of intangible cultural heritage. In this process, virtual reality and man-machine interaction are the technological base of interactive display. Supported by network techniques and related protocols and standards, these display platforms can not only combine with Heritage Museum, but carry out online display independently. Currently, the support for propagation and sharing of intangible cultural heritage from mass media and we media remains to be insufficient.

4) Protection and development of intangible cultural heritage: Protection and development of intangible cultural heritage by three-dimensional animation can be interdependent. Reasonable development and innovation not only conserve the tradition, but create or derive new forms meeting modern culture, which helps the intangible cultural heritage get new living space under marketization, leading to proper inheritance and development of intangible cultural heritage in the contemporary civilization. Now main units conducting protection of intangible cultural heritage are scientific research institutions, colleges and universities, libraries and museums etc. Though relevant dissemination produced by animation companies and propagated via media such as TV, networks and films are rare, it is a mode worth discussion and popularization.

\section{New Mode of Protection of Intangible Cultural Heritage by Commercial three-Dimensional Animation}

"Little Master of Brocade" (Yun Jing Xiao Dang Jia) is a 3D animated cartoon produced by Jiangsu Yintu Culture Development Co., Ltd, a company aiming at promoting excellent traditional Chinese culture and the quintessence of Chinese culture and inheriting classical original culture. Just as Pixar Animation Studios, a well-known American animation company, laid technological and marketing foundations for its "Toy Story", the first complete 3D animated film in the world released in 1994, by distributing "Tin Toy" in 1988 and "Knick Knack" in 1989, Jiangsu Yintu first produced "God's Silk" (Chuan Ren) (See: Figure 1) and "Legend of Brocade" (Yun Jing De Chuan Shuo) (See: Figure 2)before "Little Master of Brocade" (Yun Jing Xiao Dang Jia). "God's Silk" (Chuan Ren) won the Best Short Film Award of the First Short Film Competition of Jiangsu, was shortlisted for the KingBonn Award of The $4^{\text {th }}$ China International New Media Short Film Festival, the work exhibition of The $6^{\text {th }}$ Global Chinese Universities Student Film and TV Festival, selected for the $3^{\text {rd }}$ Panorama of the China Independent Animation Film Forum and shown on the Milan Expo in July 2015. "Legend of Brocade" (Yun Jing De Chuan Shuo) is an ink-and-wash animated short film shortlisted for the Cyber Sousa in 2013 and also one of the invited films for the Lisbon animation festival of Portugal in March 2014. In addition, it was showed in the Museum of Chinese Historical Materials, Paris, France for the 50th Anniversary of the Establishment of Diplomatic Relations between China and France.

These two short films laid a solid foundation for the 3D animation technology applied to "Little Master of Brocade" (Yun Jing Xiao Dang Jia). Meanwhile, they attracted marketing and investment channels at home and abroad. According to the news from JSCHINA. COM. CN, "The Provincial Angel Investment Alliance holds the first Yuanquxing Meeting. "Little Master of Brocade" (Yun Jing Xiao Dang Jia), a 3D animated cartoon, has drawn attention of a famous foreign film and TV communication company on MIPTV and now is badly in need of two million yuan for production of some quality episodes. More than 60 enterprises and 35 projects were first examined by the Provincial Angel Investment Alliance in the national science park of Southeast University". Therefore, "Little Master of Brocade" (Yun Jing Xiao Dang Jia) had gained attention of media at that time and its financing channels will continuously increase. 


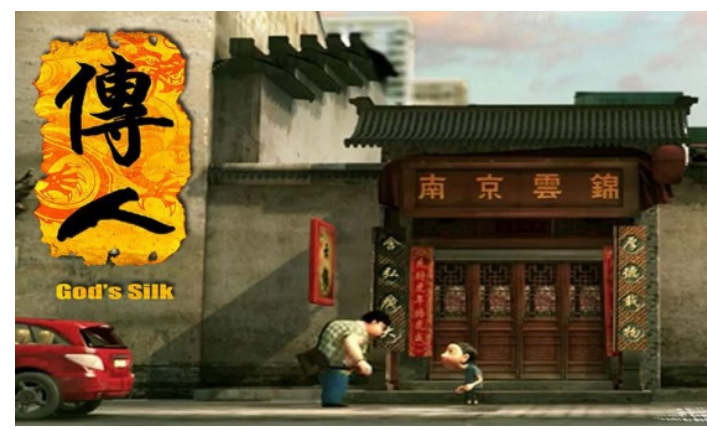

Figure 1. God's Silk (Chuan Ren)

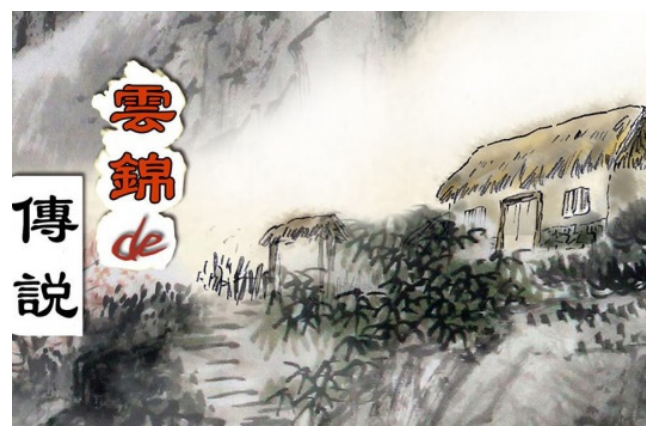

Figure 2. Legend of Brocade (Yun Jing De Chuan Shuo)

The 26-episode "Little Master of Brocade" (Yun Jing Xiao Dang Jia) is written by Chen Yan and directed by Yang Haiyan. It mainly tells a story about Ni Beibei, who enters grandma Wenjin's antique shop accidentally and gains the power of shuttling between the past and the future. To help friends from the modern and the past complete tasks of weaving brocade, Ni Beibei learns the history and the craftsmanship of brocade and becomes a new master of brocade in the end. The film adopts a narrative style of fairy tales and the first perspective of the protagonist and represents history, humanity, manufacturing technology and future development of brocade through reasonable plots in the round. Compared with simple cartoons of science popularization, its plots make it more interesting and entertaining and audiences can Chinese learn intangible cultural heritage unknowingly.

Nanjing Brocade shown in "Little Master of Brocade" (Yun Jing Xiao Dang Jia) has a history of 1580 years and is one of China's four famous brocades with Tapestry from Sichuan, Suzhou's Song Brocade and Guangxi's Zhuang Brocade. Nanjing Brocade epitomizes brocade crafts through the ages and were a royal tribute during dynasties of Yuan, Ming and Qing. Experts regard it as the last milestone on the history of China's ancient brocade craft because of its rich cultural and scientific connotation. It was listed into the National Intangible Cultural Heritage on May 20, 2006 and the UNESCO Masterpieces of the Oral and Intangible Heritage of Humanity on September 30, 2009.

Nanjing Brocade is weaved with the traditional Dahualou wooden loom which is 5.6 meters long, 1.4 meters wide and 4 meters tall. Every loom needs a weaver and an assistant for its operation. One loom consists of 1924 components. During operation, an assistant sits on the top of the loom to lift the warp, while a weaver sits beside the loom to weave the weft and add ornaments. During production of the film, 3D modeling was used to input the actual structure of the loom into computers (See: Figure 3). Although the weavers are typical cartoon figures, the operation of the loom in the animation was produced in accordance with real operation with 3D software.

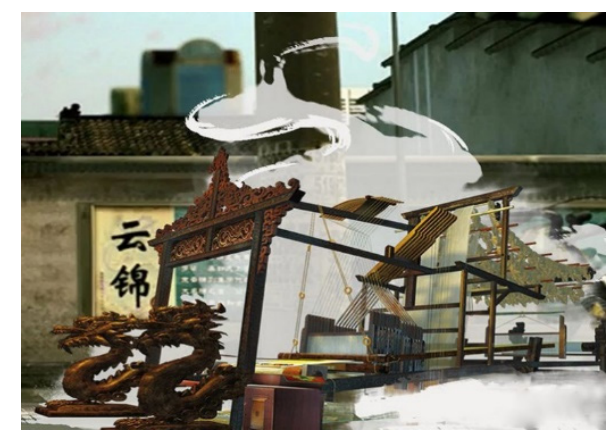

Figure 3. Little Master of Brocade (Yun Jing Xiao Dang Jia)

The craft of Nanjing Brocade is characterized by color difference of each pattern, warp run-through and weft weaving and circling weaving for patterns. The color of each flower on the cloth changes from different angle. Nanjing Brocade can present various silks and brocades on the same cloth and weave gold, silver and peacock feathers into the cloth. As Nanjing Brocade was exclusively used in royal robes for a long time, its weaving spares neither labor nor money. As a result, Nanjing Brocade is featured by rich and colorful patterns, large flowers, appealing design, bright and bold color design. In particular, the application of gold is one of its features with free color combinations and varied colors, reaching its peak of perfection. In "Little Master of Brocade" (Yun Jing Xiao Dang Jia), by using 3D mapping and rendering technology, the beauty of Nanjing Brocade is presented in 
front of audiences through animation, where it is hard to realize its composition and camera angles in photography. However, this film is also affected by limited technology and capital. If the motion capture system and scientific data from professional research institutions had been adopted during the production, the film might have become more detailed. As a commercial animation, it started with low-cost production resulted from marketization. After obtaining good market feedback, the film can be improved constantly for its subsequent theatrical version.

\section{Future Trend of Protection of Intangible Cultural Heritage by Commercial Three-Dimensional Animation}

It is necessary for commercial animation to be profitable, because it needs to support the sustained development of its team. However, animated movies with good reputation but low box office are everywhere in the domestic market. Hence, protection of intangible cultural heritage by commercial three-dimensional animation also has certain limitation. Once it encounters setback in the market, all of its previous efforts may be wasted. Therefore, it needs support policies from relevant cultural departments, social concerns and support of public opinions of media and should take an active part in the joint development with local units relenting to protection of intangible cultural heritage.

According to documents from Chinese Government Public Information Online, the "Protection Programme of Intangible Cultural Heritage of Nanjing" was formulated by the Municipal Bureau of Culture, Broadcasting, Television, Press and Publication and co-produced by the Municipal Protection Center of Intangible Cultural Heritage and Nanjing University Institute of Cultural and Natural Heritage in 2011. "According to the Programme, in next 5 years, Nanjing will establish a database of inheritors including inheritance paths, inheritance trees and audio and video materials etc., perfect a three-level inheritor protection system from the national level to the provincial and municipal levels, and evaluate representative inheritors and inheritance institutions regularly".

The commercial three-dimensional animation can not only be audio and video materials about protection of intangible cultural heritage, but store motion data by the increasingly mature motion capture system of 3D animation. For example, in the intangible cultural heritage project of protecting Chinese minority dance of Guizhou, the motion capture technology was employed to collect 3D data record of dancing postures and save 3D motion trails of dancers. Afterwards, 3D animation software was used to conduct 3D modeling and character animation of dance, so that the quintessence of folk dance arts can be preserved faithfully and roundly. The data collected by the motion capture system of 3D animation can not only be input in 3D models for animation production and preservation and analysis of 3D image data of intangible cultural heritage, but provide reference data and coefficients for the artificial intelligence system, laying a foundation for the inheritance of the technology relenting to intangible cultural heritage in the future robot technology.

The most important task of protection of intangible cultural heritage is to make it into an organic part of modern people's cultural life, so that it can be inherited, survive and be developed in today's cultural environment, leading to good protection of modern cultural diversity and benign development of contemporary cultural ecology.

Propagation of intangible cultural heritage by commercial three-dimensional animation is the second creation of intangible cultural heritage by three-dimensional animation. It enhances propagation modes of intangible cultural heritage and allows more people to know intangible cultural heritage. Moreover, it promotes animation creation in respect of Chinese culture and commercial teams join in the protection of intangible cultural heritage as a supplement role. Hence, instead of simple addition and overlapping of three-dimensional animation and intangible cultural heritage, it is a creative art form and a bilateral interaction and a win-win result of commercial animation and traditional culture.

\section{Acknowledgements}

This research is supported in part by the Philosophy and Social Science Foundation of Jiangsu Universities (2012SJB760025)

\section{References}

Cai, Q., \& Lu, J. (2009). Motion-capture-technology-based research on digital protection of Chinese minority dance of Guizhou. Journal of Guizhou University (Natural Science Edition), 26(4). http://dx.doi.org/10.15958/j.cnki.gdxbzrb.2009.04.032

Gao, X. K. (2008). Intangible cultural heritage: rethinking on its protection and utilization. Exploration and Free Views, 4 , 65-67.

Little Master of Brocade (Yun Jing Xiao Dang Jia). (2013, March 30). In Sohu. Retrieved March 30, 2013, from http://roll.sohu.com/20130330/n371017008.shtml 
Lu, D. M, Diao, C. Y., \& Liu, D. Z. (). Digital technology of cultural relics and its application (pp. 27-36). The $2^{\text {nd }}$ Symposium on Digitization and Protection of Chinese Cultural Heritage.

Luo, J. Y., \& Zhong, L. (2015). Research on application of digital technology of intangible cultural heritage products from a low-carbon perspective. Packaging Engineering, 36(10), 9-12.

Pieraccini, M., Guidi, G., \& Atzeni, C. (2001). 3D digitizing of cultural heritage. Journal of Cultural Heritage, 2(1), 63-70. https://doi.org/10.1016/S1296-2074(01)01108-6

\section{Copyrights}

Copyright for this article is retained by the author(s), with first publication rights granted to the journal.

This is an open-access article distributed under the terms and conditions of the Creative Commons Attribution license (http://creativecommons.org/licenses/by/3.0/). 